[2] Zureik M, Touboul PJ, Bonithon-Kopp C, et al. Cross-sectional and 4-year longitudinal associations between brachial pulse pressure and common carotid intima-media thickness in a general population. The EVA study. Stroke 1999;30(3):550-5. doi: 10.1161/01.str.30.3.550

Table 1. Demographic characteristics.

\begin{tabular}{|c|c|c|c|}
\hline & RA (n=92) & Control $(n=92)$ & $p$ \\
\hline Women, n (\%) & $85(92.4)$ & $85(92.4)$ & NS \\
\hline Age, years \pm SD & $58.0(55.0-63.0)$ & $56.5(54.0-61.0)$ & NS \\
\hline T2DM, n (\%) & $17(18.5)$ & $15(16.3)$ & NS \\
\hline Hypertension, n (\%) & 33 (35.9) & $33(35.9)$ & NS \\
\hline Dyslipidemia, $n(\%)$ & $30(32.6)$ & $29(31.5)$ & NS \\
\hline Obesity, n (\%) & $30(32.6)$ & 31 (33.7) & NS \\
\hline \multirow[t]{2}{*}{ Active smoking, n (\%) } & $11(12.0)$ & $20(21.7)$ & NS \\
\hline & $\begin{array}{c}\text { RA patients with CP } \\
(n=39)\end{array}$ & RA patients without & $p$ \\
\hline Women, n (\%) & $36(92.3)$ & $49(92.5)$ & NS \\
\hline Age, years $\pm S D$ & $60.13 \pm 5.98$ & $58.08 \pm 7.00$ & NS \\
\hline T2DM, n (\%) & $9(23.1)$ & $8(15.1)$ & NS \\
\hline Hypertension, n (\%) & $16(41.0)$ & $17(32.1)$ & NS \\
\hline Dyslipidemia, n (\%) & $13(33.3)$ & 17 (32.1) & NS \\
\hline Obesity, n (\%) & 15 (38.5) & 15 (28.3) & NS \\
\hline Active smoking, $n(\%)$ & $6(15.4)$ & $5(9.4)$ & NS \\
\hline Disease duration, years & $8.44(3.00-15.50)$ & $12.86(4.66-19.66)$ & NS \\
\hline
\end{tabular}

NS, no significant; T2DM, type 2 diabetes mellitus; CP, carotid plaque.

Figure 1. Comparison of pulse pressure between RA and controls and, RA with and without carotid plaque

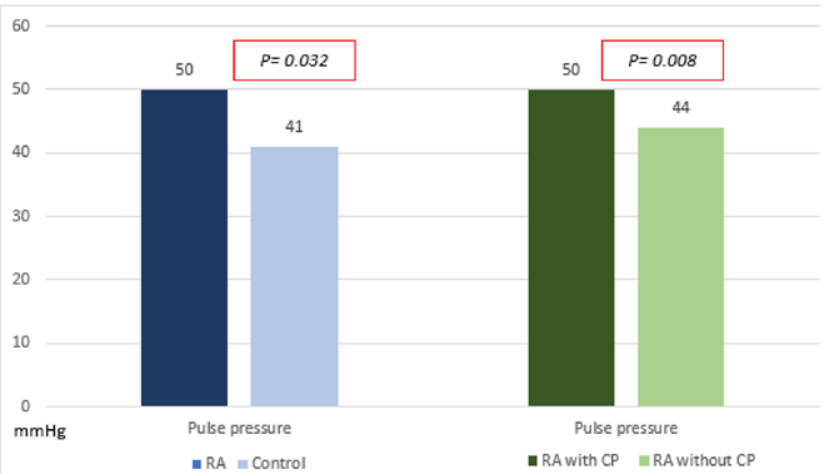

Disclosure of Interests: None declared

DOI: 10.1136/annrheumdis-2021-eular.3005

\section{POS0563 1 THE NATURAL COURSE OF RHEUMATOID ARTHRITIS- ASSOCIATED INTERSTITIAL LUNG DISEASE FOCUSING ON LUNG PHYSIOLOGY AND DISEASE ACTIVITY: A PROSPECTIVE COHORT STUDY (PART 2)}

S. H. Chang ${ }^{1}$, J. S. Lee' ${ }^{2}$, J. S. Lee ${ }^{3}$, C. H. Park ${ }^{4}$, M. U. Kim ${ }^{5}$, Y. J. Ha ${ }^{6}$, E. H. Kang ${ }^{6}$, Y. A. Lee ${ }^{7}$, Y. Park ${ }^{8}$, J. Y. Choe ${ }^{9}$, E. Y. Lee ${ }^{10}$ on behalf of KOrean Rheumatoid Arthritis Interstitial Lung disease (KORAIL) cohort study group. ${ }^{1}$ Soonchunhyang University College of Medicine, Division of Rheumatology, Department of Internal Medicine, Cheonan, Korea, Rep. of (South Korea); ${ }^{2}$ Clinical Research Center, Asan Institute for Life Sciences, Asan Medical Center, Department of Medical Stastics, Seoul, Korea, Rep. of (South Korea); ${ }^{3}$ GENOME INSIGHT Inc., -, Seoul, Korea, Rep. of (South Korea); ${ }^{4}$ Soonchunhyang University College of Medicine, Department of Radiology, Cheonan, Korea, Rep. of (South Korea); ${ }^{5}$ SMG-SNU Boramae Medical Center, Department of Radiology, Seoul, Korea, Rep. of (South Korea): ' 6 Seoul National University Bundang Hospital, Division of Rheumatology, Department of Internal Medicine, Seongnam, Korea, Rep. of (South Korea); ${ }^{7}$ Kyung Hee University College of Medicine, Division of Rheumatology, Department of Internal Medicine, Seoul, Korea, Rep. of (South Korea); ${ }^{8}$ Yonsei University College of Medicine, Division of Rheumatology, Department of Internal Medicine, Seoul, Korea, Rep. of (South Korea); ${ }^{9}$ Catholic University of Daegu College of Medicine, Division of Rheumatology, Department of Internal Medicine, Daegu, Korea, Rep. of (South Korea); ${ }^{10}$ Seoul National University College of Medicine, Division of Rheumatology, Department of Internal Medicine, Seoul, Korea, Rep. of (South Korea)

Background: Interstitial lung disease (ILD) is a severe extra-articular manifestation of rheumatoid arthritis (RA). However, the effect of RA disease activity on the course of ILD is not yet known.

Objectives: To assess the natural course of lung physiology of RA-ILD and the relation between arthritis activity and pulmonary physiology in patients with RA-ILD.
Methods: The Korean Rheumatoid Arthritis ILd (KORAIL) cohort is the prospective observational cohort and aims to investigate the natural course of RAILD. Based on either 1987 or 2020 ACR criteria, patients diagnosed with RA and ILD based on CT scan were recruited from six tertiary medical hospitals in Korea since January 2015. RA disease activity was assessed using disease activity (DAS)28-ESR and CRP, annually. Pulmonary function tests (PFT), including FVC and DLCO were conducted annually. According to the transition of DAS28-ESR status, we classified patients into four groups: Group A. persistent remission or low disease activity, Group B. improvement, Group C. worsening, Group D. persistent moderate to high disease activity.

Results: We analyzed 143 patients who completed a 2-year follow-up (visit 2) or had died with available PFT results at least twice. Mean duration since RA diagnosis and since ILD diagnosis was $7.6 \pm 8.0$ and $2.7 \pm 3.1$ years, respectively. Twenty-four patients were Group A, 33 Group B, 10 Group C and 30 Group D. The mean of $F V C(\mathrm{~mL})$ and \% of the predicted value in $\mathrm{FVC}$ was significantly lower in Group D than in other groups (Table 1). The annual rate of decline in FVC was $-42(95 \% \mathrm{Cl}-93 \sim 10) \mathrm{mL}^{-y e a r^{-1}}$ in Group B while $-113(95 \% \mathrm{Cl}-206$ 21) $\mathrm{mL} \cdot$ year $^{-1}$ in Group $C$ (Figure 1A). The annual decline rate in Group $C$ was further exaggerated in patients with $\geq 80 \%$ of FVC predicted $(-141,95 \% \mathrm{Cl}$ $\left.-251 \sim 32 \mathrm{~mL} \cdot \mathrm{year}^{-1}\right)$. During two years of follow-up, patients ever experienced a relative decline of $\geq 10 \%$ from the enrollment in FVC predicted was $27.3 \%(n-9 / 33)$ in Group B whereas $30.0 \%(3 / 10)$ in Group C. The annual rate of decline in \% of DLco predicted value was also the largest in Group C $\left(-4.6 \% \cdot\right.$ year $^{-1}, 95 \% \mathrm{Cl}$ $-8.5 \sim-0.7)$, which further exaggerated in patients with $\geq 80 \%$ of FVC predicted $\left(-4.9 \% \cdot\right.$ year $^{-1}, 95 \% \mathrm{Cl}-8.3 \sim-1.5$, Figure $\left.1 \mathrm{~B}\right)$. Of note, about half of patients with maintained not only low disease activity (Group A) but also moderate to severe disease activity (Group D) improved in DLco at least $10 \%$ or more from the enrollment of DLco predicted value (Group A: $54.2 \%, n=13 / 24$, Group D: $46.7 \%$, $n=14 / 30$ )

Conclusion: RA disease activity is associated with the change of lung physiology in patients with RA-ILD; worsening disease activity associated with a further decrease of annual change in FVC and maintaining low disease activity associated with a further increase of annual change in $\%$ of DLco predicted value.

Table 1. The analysis of forced vital capacity (FVC) according to disease activity transition group.

\begin{tabular}{|c|c|c|c|c|}
\hline & Group A & Group B & Group C & Group D \\
\hline $\mathrm{FVC}(\mathrm{mL}), \mathrm{mean} \pm \mathrm{SD}$ & $2810.0 \pm 771.1$ & $2528.8 \pm 735.3$ & $2801.0 \pm 952.7$ & $2048.3 \pm 575.7$ \\
\hline FVC $\%$ of predicted, mean \pm SD & $87.5 \pm 14.5$ & $86.5 \pm 16.6$ & $93.0 \pm 15.6$ & $77.2 \pm 17.3$ \\
\hline $\begin{array}{l}\text { Rate of FVC decline, } \mathrm{mL} \cdot \mathrm{year}^{-1} \\
\qquad(95 \% \mathrm{Cl})\end{array}$ & $-52(-112,7)$ & $-42(-93,10)$ & $-113(-206,-21)$ & $1(-52,54)$ \\
\hline $\begin{array}{l}\text { A 10-point decline from V1 in } \\
\text { predicted FVC value, } n(\%)\end{array}$ & $29(20.3)$ & $6(25.0)$ & $6(18.2)$ & $3(30.0)$ \\
\hline $\begin{array}{l}\text { Relative decline of } 10 \% \text { from the } \\
\text { enrollment in predicted FVC } \\
\text { value, } n(\%)\end{array}$ & $35(24.5)$ & $5(20.8)$ & $9(27.3)$ & $3(30.0)$ \\
\hline
\end{tabular}
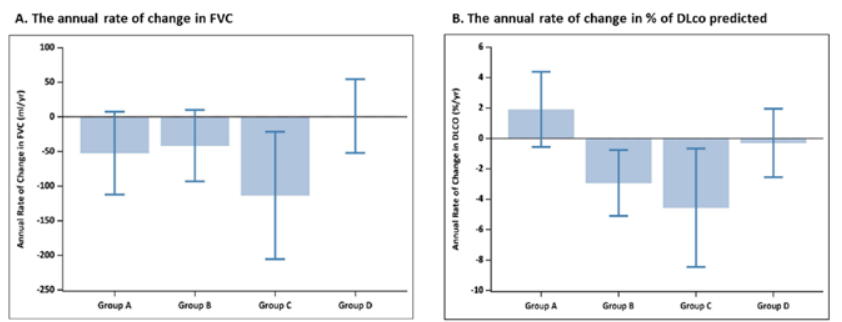

Figure 1. The annual change of pulmonary physiology according to disease activity transition group.

Acknowledgements: This work was supported by the Korea Health Technology R\&D Project through the Korea Health Industry Development Institute, funded by the Ministry of Health and Welfare, Republic of Korea (grant no.HI14C1277). Disclosure of Interests: None declared

DOI: 10.1136/annrheumdis-2021-eular.3084

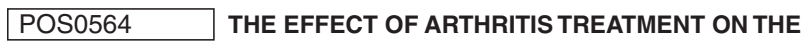 COURSE OF RHEUMATOID ARTHRITIS-ASSOCIATED INTERSTITIAL LUNG DISEASE FOCUSING ON BIOLOGIC DMARDS: FROM A PROSPECTIVE COHORT STUDY (PART 5)}

S. H. Chang ${ }^{1}$, J. S. Lee ${ }^{2}$, J. S. Lee ${ }^{3}$, C. H. Park ${ }^{4}$, M. U. Kim ${ }^{5}$, Y. J. Ha ${ }^{6}$, E. H. Kang ${ }^{6}$, Y. A. Lee ${ }^{7}$, Y. Park ${ }^{8}$, J. Y. Choe ${ }^{9}$, E. Y. Lee ${ }^{10}$ on behalf of KOrean Rheumatoid Arthritis Interstitial Lung disease (KORAIL) cohort study group. 